\title{
O Engenho dos Movimentos Sociais: reforma agrária e significação social na zona canavieira de Pernambuco
}

(Rio de Janeiro: Ed. Garamond, 2011)

Camila Penna ${ }^{1}$

E m O Engenho dos Movimentos Sociais: reforma agrária e significação social na zona canavieira de Pernambuco, Marcelo Rosa traz valiosas contribuições para a teoria sociológica e para o estudo dos movimentos sociais rurais no Brasil. O livro aborda o processo de expansão do MST na Zona da Mata pernambucana e discute os efeitos dessa expansão para o tradicional sindicalismo rural da região. Além disso, traz, como seu mais significativo aporte, a noção de "forma movimento", desenvolvida ao longo do livro para designar a forma que foi adquirindo um significado legítimo, perante o Estado, para se reivindicar terra.

Partindo do conceito de "figuração", de Norbert Elias, o autor se distancia das interpretações estruturalistas e tradicionais para analisar o processo de multiplicação das ocupações de terra e dos movimentos sociais que tomou lugar na Mata pernambucana no final dos anos 1990. Com efeito, a compreensão de que os processos sociais não podem ser entendidos somente a partir dos atributos dos indivíduos, nem tampouco a partir de atributos de um sistema ou de uma totalidade, mas sim a partir de uma rede de interdependências que liga os sujeitos sociais, tem implicações para a análise de Marcelo Rosa. O crescimento no número de ocupações de terra em Pernambuco ao longo dos anos 1990 é explicado a partir da explicitação de vários elementos interdependentes que resultaram em uma figuração específica das relações sociais naquele contexto: o declínio dos setores sucroalcooleiros no estado em decorrência da política do governo de retirada dos incentivos financeiros; a expansão e o trabalho de base do MST; a incapacidade dos sindicatos de continuar garantindo os direitos trabaIhistas pelos quais historicamente haviam lutado; o reconhecimento, pelo Estado, da ocupação e do acampamento como formas legítimas de reivindicação; e a eficácia do engajamento em movimentos sociais para a significação social das pessoas naquele contexto.
1. Doutoranda em Sociologia na Universidade de Brasília.

E-mail:

camilapenna2003@ yahoo.com 
Após uma pesquisa de três anos que envolveu levantamento de arquivos oficiais, entrevistas e etnografia de eventos como a eleição da diretoria da Fetape, o autor vai tecendo a rede de interdependências e nos inserindo no mundo da mata pernambucana com toda sua complexidade, não nos deixando, contudo, cair na tentação de tirar conclusões precipitadas baseadas em interpretações sociológicas canônicas. A partir da apresentação de evidências e pistas encontradas no campo, Marcelo Rosa vai desconstruindo interpretações tradicionais que explicam a história dos movimentos rurais a partir de um viés classista ou da noção de "utopia camponesa". Ao descrever atentamente o processo de mudança nas relações sociais da Mata pernambucana que estava tomando lugar no contexto de proliferação da luta pela terra, o livro também põe em cheque as habituais noções sociológicas que associam o mundo rural ao tradicional e ao atrasado.

A narrativa, aparentemente centrada nas pessoas, vai desvendando o intrincado mundo de organizações, eventos, situações e relações sociais que dá sentido às ações das lideranças dos movimentos sociais. É a partir da observação perspicaz das redes de interdependência, nas quais estão inseridas cada uma dessas lideranças, e do significado social que suas ações adquirem nesses contextos, que Marcelo Rosa enuncia o argumento central de seu trabalho: "as ocupações só ocorrem porque existem pessoas dispostas a organizá-las e essa disposição os arrebata, apesar de terem interesses completamente distintos, porque encontram nessa atividade uma forma eficaz de significação social” (p. 215). Nesse sentido, ao mesmo tempo em que traça diferentes possíveis explicações para o engajamento dos militantes, o autor toma o cuidado de não oferecer uma interpretação que sirva como modelo de militância no MST e em outros movimentos de luta pela terra.

Com efeito, a primeira parte do livro descreve o momento de chegada do MST na região canavieira de Pernambuco no final dos anos 1980, em um contexto no qual os códigos sociais ligados à organização sindical e aos repertórios de luta do sindicalismo tradicional ainda eram dominantes. Descreve também o processo e engajamento das principais lideranças do MST na região, assinalando para a importância tanto do corte geracional como do estigma social vivenciado por essas lideranças. Furtando-se de propor um modelo ou uma interpretação generalizável para a militância no MST e demonstrando honestidade face aos dados nem sempre coerentes que obteve durante as entrevistas com os militantes, Marcelo Rosa assinala para a participação no movimento como elemento que confere às pessoas significação social nos diferentes contextos em que se inserem. Pessoas antes estigmatizadas ou muito jovens passam a ser respeitadas na medida em que coordenam e organizam ocupações e acampamentos com centenas de famílias, passando a se reunir com autoridades como 
prefeitos e representantes do INCRA.

A segunda parte do livro demonstra, por meio de descrições argutas e de etnografia do processo eleitoral da diretoria da Fetape em 2002, como os novos códigos sociais expressos em categorias como ocupação, acampamento e movimento foram sendo incorporados pelo sindicalismo tradicional e pelo Estado. $\mathrm{O}$ autor explica, primeiramente, porque os códigos sociais ligados ao sindicalismo tradicional e ao seu repertório de luta eram tão fortes, na medida em que conferiam significação social às pessoas a eles associadas por serem reconhecidos e legitimados a partir da relação com o Estado. A partir da descrição do significado que os códigos sociais antigos tinham para as pessoas mais velhas que assumiam a direção da Fetape, a narrativa de Marcelo Rosa deixa claro porque foi tão difícil o processo de mudança no interior da Federação. Deixa claro porque, em um contexto de proliferação da luta pela terra na região canavieira de Pernambuco, a Fetape resistiu à adoção dessa agenda e do repertório de luta ligado a ela: ocupação de terra e estabelecimento de um acampamento. A etnografia do processo eleitoral da diretoria da Federação, no contexto do aumento das forças internas e externas a favor da bandeira da reforma agrária e da ocupação de terras, é elucidativa do momento de mudança e ruptura vivenciado pelo sindicalismo tradicional da Mata pernambucana.

Para averiguar qual era o significado e quais eram as dimensões dessa mudança, o autor volta ao campo, em 2003, e acompanha os eventos Grito da Terra Brasil e a ocupação da sede do INCRA, organizados pela nova diretoria da Fetape. A observação desses processos resulta em algumas das mais interessantes contribuições do livro, juntamente com os elementos trazidos na terceira e última parte. As eleições para a diretoria da Fetape terminaram com a vitória do grupo que defendia o sindicalismo tradicional e com a derrota do grupo que defendia a bandeira da reforma agrária. Contudo, alguns meses depois a Federação havia passado por um processo de mudança e havia adotado não só a reforma agrária como parte de sua pauta, mas também os códigos sociais ligados a essa reivindicação: fabricação de bonés e bandeiras, ocupação do INCRA e ocupação de propriedades. A observação da ocupação da sede do INCRA leva o autor a perceber a importância definitiva do Estado para a legitimação desses novos códigos sociais: "o elemento que permitia a imposição da unidade da Fetape era, do meu ponto de vista, o Estado, que naquele dia recebia com parcimônia seus diretores" (p. 154). Também o leva a concluir que estava tomando lugar um processo de mudança social no contexto das relações sociais dos sindicalistas da Mata pernambucana. Ao passo que, antes, as negociações se davam primordialmente com o patrão ou dono do engenho, atualmente, as cada vez mais presentes negociações por reforma agrária eram "invariavelmente conduzidas pelas instituições estatais". 
A partir dos dados que Marcelo Rosa apresenta, fica clara a importância do Estado para a conformação dos movimentos sociais de luta pela terra. A forma pela qual o autor olha para essa relação resulta na importante constatação de que a ação dos movimentos tem como efeito o fortalecimento do Estado e não seu enfraquecimento ou deslegitimação, na medida em que, ao estabelecer o conflito, ocupando uma terra, os movimentos chamam o Estado a agir em locais onde antes ele não estava presente. Por outro lado, o autor mostra como ir ao INCRA, seja por meio de ocupação ou através da negociação com o superintendente, tem importância para o estabelecimento dos movimentos, uma vez que é o momento de legitimação e de reconhecimento. Essas constatações problematizam as interpretações que dicotomizam a relação entre Estado e movimentos sociais a partir das noções de autonomia e de cooptação.

Na última parte do livro, as contribuições de Marcelo Rosa para os estudos dos movimentos sociais de luta pela terra e de suas relações com o Estado vão se desenrolando ao longo da descrição dos vários movimentos que ocupam terra, na Mata pernambucana, e ao final aparecem nitidamente com a noção de "forma movimento". Partindo da observação dos vários movimentos que atuam na região canavieira de Pernambuco, o autor percebe que, por mais diferentes que fossem suas composições, tendência, orientação e idade, todos eles adotavam um formato específico de ação. Esse formato, caracterizado pela presença de uma bandeira, de bonés, camisetas, hinos e outras simbologias específicas, além do essencial repertório de ocupação da sede do INCRA, exercia um papel fundamental de linguagem na relação com o Estado. Em outras palavras, esse era o formato de apresentação reconhecido pelo INCRA como legítimo para os atores que reivindicavam reforma agrária. A essa forma de representação que adquiria cada vez mais um significado legítimo para o Estado - em grande medida devido ao repertório adotado pelo próprio MST e difundido para outros movimentos, na medida em que estes também almejavam ser reconhecidos como interlocutores legítimos dos sem terra - o autor designa "forma movimento": "como vimos no caso da Comissão Pastoral da Terra, com o passar do tempo, o próprio Estado (Incra) passou simbioticamente a criar formas de interlocução e ação que se sustentam sobre a categoria movimento. Agindo assim, acabou reforçando a ideia de que, sem movimento, não há reforma agrária nos dias de hoje" (p.182).

Ao cunhar o termo "forma movimento", Marcelo Rosa aprofunda a contribuição teórica de Lygia Sigaud, que havia criado a noção de "forma acampamento" para designar a linguagem e o tipo de repertório de ação coletiva reconhecido pelo Estado para se reivindicar terra. Ambos os conceitos são essenciais para se compreender como o INCRA dá significado às demandas por reforma agrária e aos futuros beneficiários de suas políticas. A noção "forma movimento", 
que condensa a compreensão certeira e perspicaz do autor sobre a relação entre o INCRA e os movimentos sociais de luta pela terra, é o aporte mais relevante do livro. Contribui não somente para a compreensão das relações entre Estado e movimentos sociais, como também para a compreensão dos efeitos dessas relações para a forma de organização das lutas no campo e para o processo de formulação das politicas públicas de reforma agrária.

\section{Referências Bibliográficas}

ELIAS, Norbert. O Processo Civilizador: uma história dos costumes. Vol. II. Rio e Janeiro: Jorge Zahar Editor, 1990.

. A Sociedade dos Indivíduos. Rio e Janeiro: Jorge Zahar Editor, 1994.

SIGAUD, Lygia. A Forma Acampamento: notas a partir da versão pernambucana. Novos Estudos Cebrap, n. 58, 2000.

. As condições de possibilidade das ocupações de terra. Revista Tempo Social, São Paulo, SP, v. 17, n. 1, 2005, p. 255-280. 